\title{
Money isn't everything - CMSA doctor survey shows some noteworthy results
}

South Africa (SA) can ill afford to lose medical doctors to emigration. Retention of skills is critical for the functioning of the public sector that needs to deliver on the healthcare needs of over $80 \%$ of South Africans. Unfortunately, we continue to see two trends in our healthcare industry, these being:

- Medical doctors leaving SA

- Shortages of medical doctors wishing to fill key posts in the public sector, due to the migration of doctors into the private sector or abroad, or posts being frozen or becoming unfunded.

There are many theories as to why medical doctors choose to leave public service and emigrate.

Remuneration is most often postulated as the main driver, with stakeholders resigning themselves to the fact that this is the lot of a developing country and there is little that can be done to reverse this trend.

But is the lure of the dollar and the pound the main driver of emigration? Is money the main reason why doctors leave public service?

To help stakeholders gain a better understanding of these matters, the Colleges of Medicine of South Africa (CMSA) conducted a survey to test doctors' attitudes on key matters. This survey was initially distributed to the CMSA membership and later by the South African Medical Association (SAMA) to its members.

The main objectives of the survey were to better understand:

- Why doctors move from the state sector to private practice

- Why doctors choose to emigrate

- Doctors' views on whether their working environment is conducive to delivering quality care.

A total of 2229 doctors completed the CMSA survey, revealing some interesting results.

\section{Why do doctors move from the state sector to private practice?}

The most significant reason doctors gave for leaving the public sector was dissatisfaction with working conditions. Workplace security was also tabled as a more important factor than financial remuneration. The $z$-score of the hypothesis test of the proportion of doctors who rated 'Better working environment' as 10 compared with the proportion who rated 'Better workplace security' as 10 was 9.7838 . The difference between these two proportions is significant at a 0.05 significance level.

Not only were these cited as the main reason for leaving public service by doctors who had done so, but they were the main reasons given by doctors who worked in the public sector for why colleagues had left.

From a policy perspective, this sends a clear message. Workplace conditions must be considered as an integral part of any initiative to retain doctors in the public sector.

Fig. 1 reflects the responses given for each reason for leaving or considering leaving the public sector. Respondents were asked to score the importance of reasons for leaving the public sector, scored from 1 (less important) to 10 (very important). From Fig. 1 it is very clear that the need for a better working environment is the main

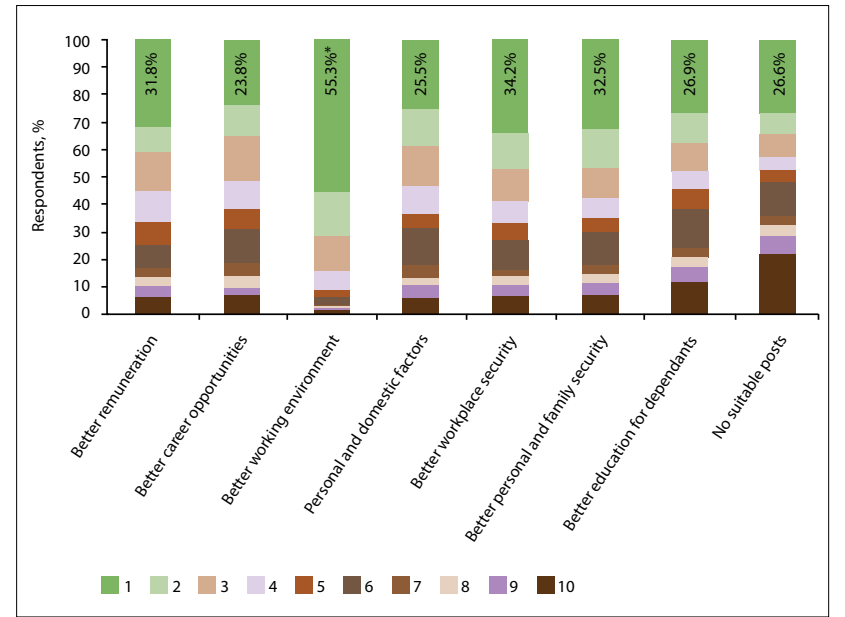

Fig. 1. Reasons for leaving or considering leaving the public sector, scored from 1 (very important) to 10 (less important). $\left({ }^{*}\right.$ Significant at $\mathrm{p}<0.05$.)

consideration for over half of the respondents (across both the public and the private sector).

All considerations (better remuneration, better career opportunities, better working environment, personal and domestic factors, better workplace security, better personal and family security, better educational opportunities for dependants and no suitable posts available) were considered important by doctors.

\section{Why do doctors choose to emigrate?}

The most significant reason given by doctors for to why they would choose to emigrate was personal and family safety and security. The second most important consideration was the attraction of a better working environment. The $z$-score of the hypothesis test of the proportion of doctors who rated 'Better working environment' as 10 compared with the proportion who rated 'Better personal and family security' as 10 was 5.018 . The difference between these two proportions is significant at a 0.05 significance level.

Once again, doctors who had not emigrated cited these reasons as the main reason why they believed colleagues had chosen to leave SA. Interestingly, better financial remuneration was considered a less important reason why doctors thought colleagues had chosen to work outside SA.

While there is little that healthcare policy makers and stakeholders can do to address personal safety and security, as this is a national issue, all parties need to be aware that this has widespread ramifications.

Fig. 2 reflects the responses given for each reason for leaving or considering leaving SA. Respondents were asked to score the importance of reasons for leaving SA, scored from 1 (less important) to 10 (very important). From Fig. 2 it is very clear that better personal and family security was the main consideration for over $60 \%$ of the respondents (across both the public and the private sector).

The view that personal and family security, a better working environment and personal and domestic factors were more important was also supported by the views cited as to why colleagues chose to work outside SA. 


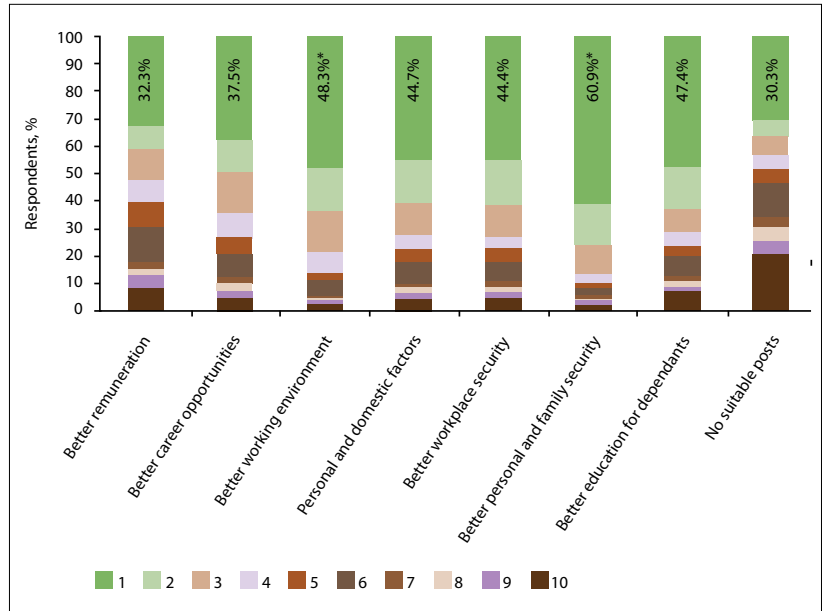

Fig. 2. Reasons for leaving South Africa, scored from 1 (very important) to 10 (less important). ( ${ }^{\star}$ Significant at $\mathrm{p}<0.05$.)

\section{The working environment}

The good news that came out of the survey was that SA doctors find their work satisfying and rewarding, with only a slight difference in private sector doctors being more positive in this regard.

Doctors also reported having good working relationships with their colleagues and reasonable senior support.

There were, however, noteworthy views regarding the workplace environment, many of which showed statistically significant differences between doctors in private practice and those in the public sector.

Doctors' views on the availability of medicine and supplies being adequate differed significantly between public sector and private sector participants, with $60.73 \%$ of public sector doctors dissatisfied with the adequacy of supplies v. $10.15 \%$ of private sector doctors $(p=0.0000)$.

A similar view was demonstrated with regard to lack of appropriate equipment/infrastructure, with $66.37 \%$ of public sector doctors indicating concern over lack of equipment and infrastructure v. only $20.41 \%$ of private sector doctors having this view $(p=0.000)$.

A similar response held true for views on facilities being of a good general standard, e.g. hygiene and management of services. In the public sector, $38.78 \%$ of employees were dissatisfied with the general facility standard v. only $5.37 \%$ of private sector doctors $(p=0.000)$.

A major concern reflected by the survey was adequacy of nursing care. Both public and private sector participants reported that nursing and other support staff were inadequate. In the private sector, $21.5 \%$ of doctors were dissatisfied with support staff v. $47.55 \%$ of public sector doctors. This finding was significant $(p=0.0000)$.

Given this input, it is not surprising that the main reason given for leaving the public sector was to ensure a better working environment.

\section{Other findings worth noting}

Both private sector and public sector doctors were unconvinced that the implementation of National Health Insurance and the introduction of the Certificate of Need would improve the delivery of healthcare in SA.

Most participants agreed that financial remuneration is important. Promotional opportunities were considered more important by public sector doctors. Opportunities for spouse and family were also considered key in determining where doctors work.

Survey participants agreed that equal opportunities for both genders and all races are important.

Opportunities for further study and research were also viewed as important, especially by public sector doctors.

Also of particular interest is that 593 participants, who were working in SA (and had qualified in SA), reported having worked internationally at some stage. The main reasons given by this group for working outside SA were travel (international experience) and financial (income generation). This suggests that many SA doctors work internationally for a period and then return to contribute to our healthcare provision. From a policy perspective, we need to guard against the view that doctors who work overseas are permanently lost to SA health.

Participation in the survey was fairly spread between doctors working in the public $(n=1108)$ and private $(n=959)$ sectors. Most participants were working in SA $(n=1840)$, the majority in Gauteng $(n=500)$, Western Cape $(n=407)$ and KwaZulu-Natal $(n=271)$ provinces. The main current clinical roles of participants were specialists in private healthcare $(n=675)$ and specialists in public service $(n=627)$. This was expected given the nature of CMSA membership, although we had hoped that the SAMA distribution would result in more responses from recently qualified colleagues.

Acknowledgements. The CMSA appreciates the co-operation and support from SAMA and its willingness to assist with the survey, which was part of the project 'Strengthening Academic Medicine and Specialist Training'. The full survey write-up is available from the CMSA on request.

Author contributions. The authors contributed equally to the writing of this article.

Funding. Funding for this project was provided by Life Healthcare. Conflicts of interest. None.

Zephne M van der Spuy, Tuviah Zabow

University of Cape Town, South Africa, and Colleges of Medicine of South Africa

Andrew Good

LifeChoice, South Africa

S Afr Med J 2017;107(7):550-551. DOI:10.7196/SAMJ.2017.v107i7.12643 